sliding against ferrous alloy. Due to the shift and combination of materials, under definite load and velocity range, the mechanically mixed layer is formed. The generated mechanically mixed layer consists of materials from both contact surfaces. It was also reported that the hardness of the generated mechanically mixed layer is greater than the bulk hardness of the composite. The generated mechanically mixed layer is majorly responsible for the decrement of wear rate and holding-up of transition to severe wear. The thickness of the mechanically mixed layer is varied with the load forms the subsurface zones of the materials as shown in Fig. 1.

Zone 1: Base material-Characterize to the base material which is not disturbed or unique sample material in the un-deformed state. Zone 1 material, when loaded in tribo-contact, encounters thermal cycling and elastic deformation. Zone 1 material's properties and structure are indistinguishable to those preceding wear tests.

Zone 2: Plastic deformation zone-Due to cyclic tribocontact, zone 2 material comprises of the part of the base sample that has acquired altered properties. Fundamentally, zone 2 material suffered a distorted transitional area of fundamental material. In zone 2 , in ductile materials, particularly plastic deformation happens, molecules are contorted \& micro voids may propagate.

Zone 3: Mechanically mixed layer-is referred to as tribolayer which generates in situ, and generally, have synthetic substance categories from counter-face and test condition and in addition the bulk material.

Doddamani et al. [3] conducted experimentation on wear behaviour of Aluminum-graphite metal matrix composites. From the results, it is found that the adding of particles of graphite has increased the resistance to wear of the metal matrix composites. Also, it is reported that the addition of particles of graphite in aluminum reduces the friction than that of the base alloy.

Rajesh et al. [4-7] conducted experimentations like hardness, wear behavior at as-cast and age hardened conditions etc. on aluminum hybrid metal matrix composites. The matrix material considered is Al7075, and reinforcement material is $\mathrm{SiC}$ and alumina. From the results, it is clear that the hybrid aluminum metal matrix composites (HAMMCs) have better properties as compared to unreinforced aluminum alloy. Mouritz et al. [8] reported changes of resistance to abrasive wear of aluminum matrix composite when subjected to the various ageing environment. In aged conditions, composite materials exhibit relatively high wear resistance.

Radhika [9] studied abrasive wear behavior of cast aluminum-SiC composite with nickel coating. For the study of wear behavior they utilized Taguchi design of experiments and Analysis of Variance (ANOVA).

The enhancement of resistance to wear in the composite is the inclusion of steel from the surface of counter face. The inclusion of steel on the worn surfaces of the

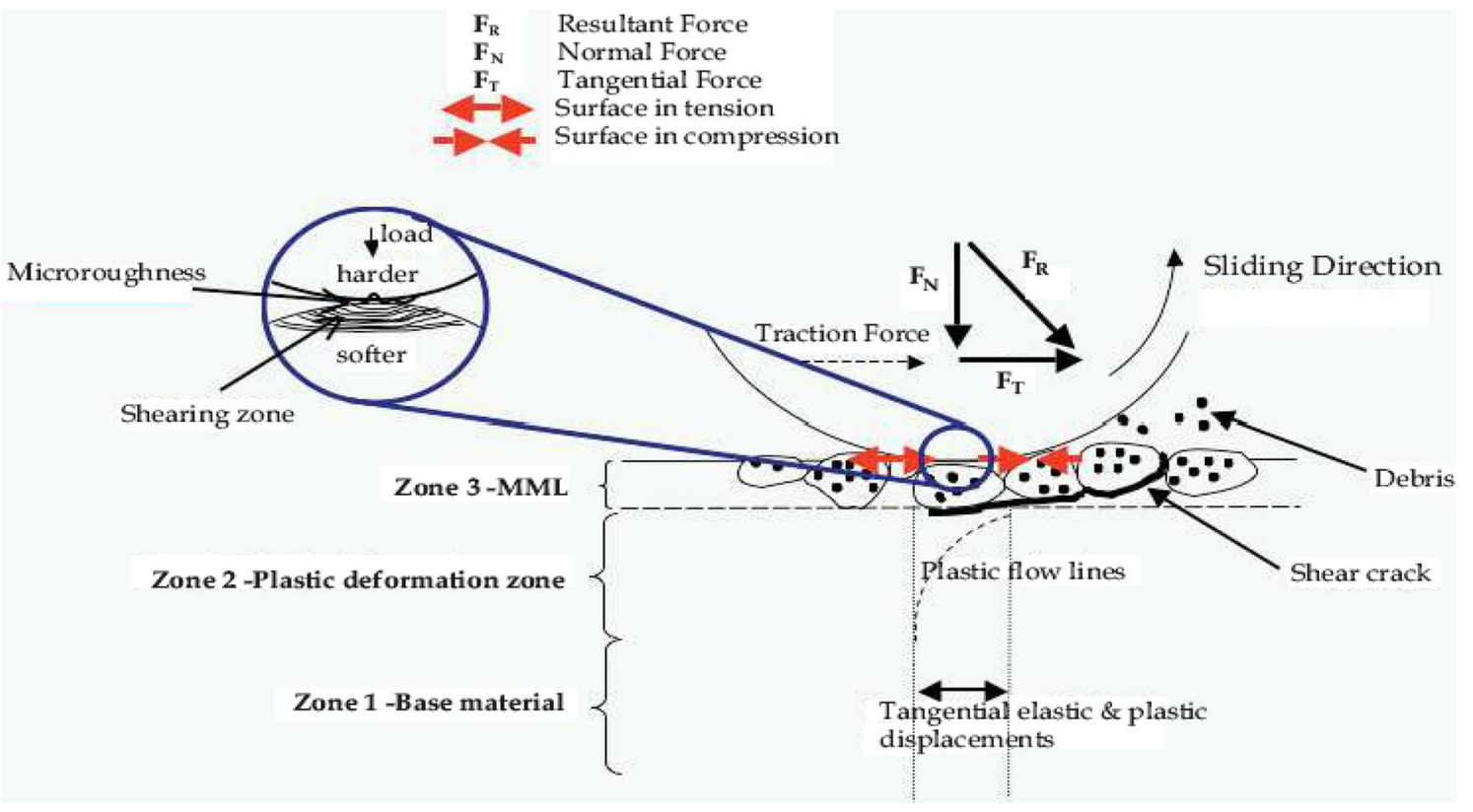

Fig. 1 MML formation [25] 
composites leads to increment the resistance of wear [10]. It demonstrates the inclusion of the steel acts as the addition of reinforcements on the wear surfaces of composites and helps to enhance the load bearing capacity [11-13]. The inclusion of the counterface material on the surface of composites leads to the generation of a thick layer called the mechanically mixed layer. The generated mechanically mixed layer serves as a lubricant and also act as a defensive layer on the worn surfaces of the composite $[14,15]$. Venkataraman and Sundararajan [16-18] reported that the transfer layer thickness increased under increasing load conditions. Due to the inclusion of steel which forms the mechanically mixed layer, reduces the rate of wear of disc and pin at high speed. High temperature is formed due to the increased speed which produces an increased amount of formation of the layer. The amount of wrap endow with the transfer layer can be found by speed, applied load, and surrounding conditions. The thickness of the layer is increased as load increases because of the increment in the heat generation and gives the superior compaction [19].

In the aluminum matrix composites, the development of tribolayer setbacks the changeovers from mild to severe wear. The exclusion of tribolayer from contact surfaces, the bulk materials becomes direct contact with the counterface and accordingly, it becomes intricate to generate another tribolayer on the heated and soft matrix [20]. Because of additional sliding, a drop in the frictional force is seen on the grounds that the mechanically mixed layer gets isolated from the pin surface, caused by delamination which exposes the fresh pin surface [21]. The outcome demonstrates that dissimilar types of reinforcement can create mechanically mixed layers. It can be accomplished that the mechanically mixed layer is created from the sources namely: counterface, matrix and the particles [22].

It is noticed from the literature that more research conducted on the wear characteristics of Al-SiCp, Al-Li/ $\mathrm{SiC}$ metal matrix composites. Although, an important scope exists for research on the aluminum matrix particulate hybrid composite reinforced with alumina, silicon-carbide mainly in the area of wear behavior and mechanically mixed layer. In this background, this research work is proposed to investigate the behaviour of aluminum matrix hard particulate reinforced composite material at different weight fraction, under different wear condition that generates the mechanically mixed layer.

The main objective of the proposed work is to develop the hybrid composite in-order to improve the strength and wear resistance characteristics of the material that generate mechanically mixed layer.

\section{Materials and processing}

\subsection{Materials}

It is identified from the literature that more research work has been done on the wear behavior of $\mathrm{Al}-\mathrm{SiC}_{\mathrm{p}^{\prime}}$ Al-graphite, Al-Fly Ash metal matrix composites. In the background, hybrid aluminum metal matrix composites have a wide range of scope for the research in wear characterization. The material selected for the research work is Al7075 as matrix and silicon carbide and alumina particles as reinforcement. The $\mathrm{Al} 7075 / \mathrm{SiC} / \mathrm{Al}_{2} \mathrm{O}_{3}$ particulate metal matrix composites are discontinuously reinforced composites which are nearly isotropic [5] and also have exceptional combinations of tribological and weight reduction properties. The motivation to utilize Al7075 is the tensile strength of the material which is higher than any other grades of the aluminum. The main constituents in the Al7075 are $\mathrm{Si}=0.4 \%, \mathrm{Zn}=6.1 \%, \mathrm{Mg}=2.9 \%$. The $\mathrm{SiC}$ material is a blend of silicon and carbon, outstanding abrasive material. Now a day, the $\mathrm{SiC}$ material is formed into a technical grade better quality ceramic with excellent mechani$\mathrm{cal} /$ physical properties. Some of the key properties of silicon carbide utilized here are Density-3.1 g/cc, melting point $-2730^{\circ} \mathrm{C}$, molecular mass $-40.10 \mathrm{~g} / \mathrm{mol}$, particle size $=100 \mu \mathrm{m}$, Appearance-Black in colour. The alumina $\left(\mathrm{Al}_{2} \mathrm{O}_{3}\right)$ is corundum. The alumina as a reinforcement is steadier with aluminum and withstand higher temperatures. Some of the key properties of aluminum oxide utilized here are density $=3.69 \mathrm{~g} / \mathrm{cc}$, melting point $-2072{ }^{\circ} \mathrm{C}$, particle size $=60 \mu \mathrm{m}$, appearance-white in colour.

\subsection{Processing}

Al7075-SiC/ $/ \mathrm{Al}_{2} \mathrm{O}_{3}$ samples are formed at varied weight fractions of $\mathrm{SiC} / \mathrm{Al}_{2} \mathrm{O}_{3}(5 \%, 10 \%$, and $15 \%)$ utilizing stir casting technique. The aluminum slabs were melted in the furnace. In the wake of liquefying, liquid aluminum was superheated to $750^{\circ} \mathrm{C}$ temperature.

The required measures of $\mathrm{SiC} / \mathrm{Al}_{2} \mathrm{O}_{3}$ particles were added to the liquid aluminum while mixing with a stirrer at $600 \mathrm{rpm}$ speed [20]. The liquid $\mathrm{Al} 7075-\mathrm{SiC} / \mathrm{Al}_{2} \mathrm{O}_{3}$ was filled a permanent mold and it was permitted to set. The Al7075-SiC/ $/ \mathrm{Al}_{2} \mathrm{O}_{3}$ composite bars were taken out from the mold. The samples were set up from as-cast combinations for investigation of required properties.

To determine the chemical composition of the said hybrid composites, Energy-dispersive X-ray (EDX) spectroscopy measurements are carried out in the SEM on individual specimens. The corresponding EDX profile analysis shown in Fig. 2 provides the atomic percentages of the elements found on the specimen surface. 


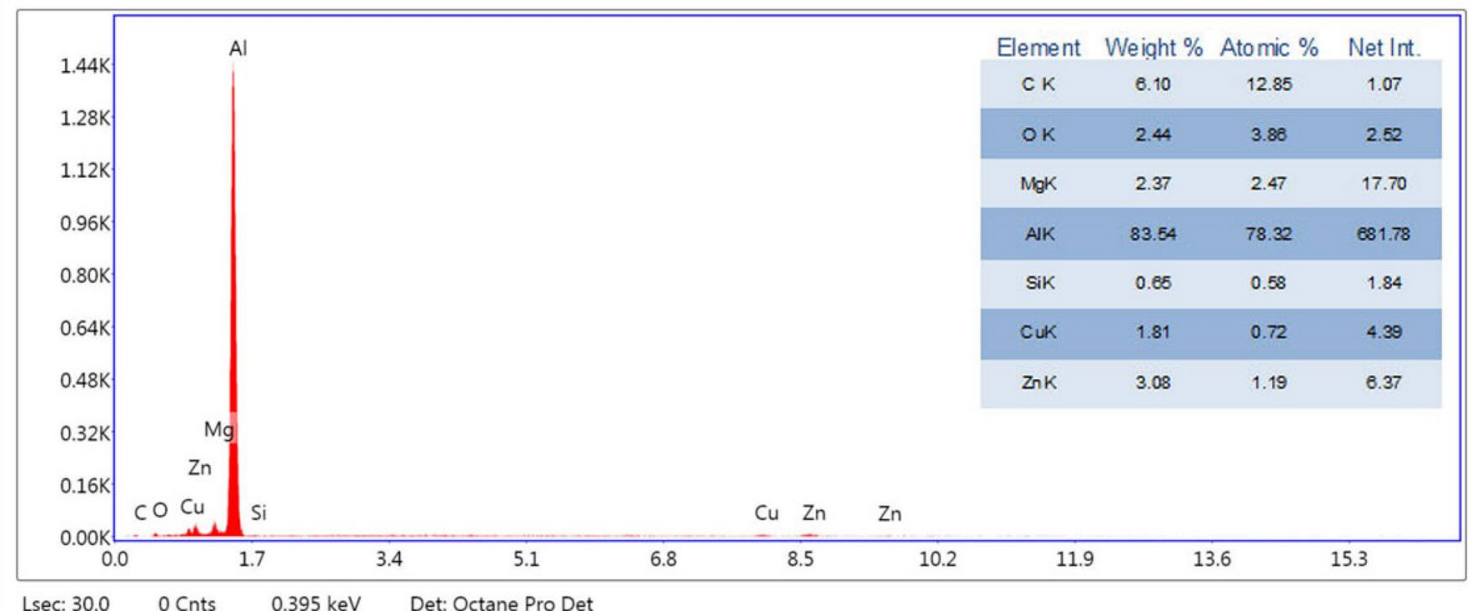

Fig. 2 EDX profile analysis for the surfaces: Al7075-10 wt $\%$ of $\mathrm{SiC} / \mathrm{Al}_{2} \mathrm{O}_{3}$ reinforcement

Table in the Fig. 2 describes the atom percentage of $\mathrm{Si}$, magnesium, carbon, and aluminum. The content of silicon, zinc and magnesium indicates that the presence of $\mathrm{Si}$ and $\mathrm{Mg}$ in the Al7075 alloy. The existence of $\mathrm{MgAl}_{2} \mathrm{O}_{4}$ at interfaces was confirmed in a detailed study on the interfaces in discontinuously reinforced metal-matrix composites. In all the compositions of Al7075-SiC, alumina, oxygen (O) content has been obtained. The content of $\mathrm{O}$ is due to the formation of $\mathrm{Al}_{2} \mathrm{O}_{3}$ on the top of the pits as the main compound on the surface [7].

The as-cast composite specimens were heat treated at a temperature of $465^{\circ} \mathrm{C}$ for $02 \mathrm{~h}$ taken after by quickly quenched in cool water. After quenching the specimens, these are subjected to an age (precipitation hardening) by heat-treatment the specimens to $120^{\circ} \mathrm{C}$, maintaining this temperature for $05 \mathrm{~h}$ and after that taken after cooling in air to room temperature.

\section{Experimentation}

Dry sliding wear experimentation for various samples is carried out by utilizing a pin-on-disc [14] wear testing machine. The machine model available in the laboratory is Wear and Friction Monitor TR-20 which was DUCOM made. The pin is held in opposition to the counterface of a rotating disk with $90 \mathrm{~mm}$ wear track diameter. The pin is subjected to a load in opposition to the disc all the way through dead weight loading systems. The wear experimentation for all samples is carried out for the load $2 \mathrm{~kg}, 4 \mathrm{~kg}, 6 \mathrm{~kg}$ and a fixed velocity of sliding of $0.942 \mathrm{~m} / \mathrm{s}$, $1.8849 \mathrm{~m} / \mathrm{s}, 2.82 \mathrm{~m} / \mathrm{s}$ for $200,400,600 \mathrm{rpm}$ respectively for about $5 \mathrm{~min}$. The pin specimens are of length $35 \mathrm{~mm}$ and diameter $10 \mathrm{~mm}$. Before the wear tests, the pins were polished by using emery paper (1000 size grit) in-ordered to make sure that efficient contact between the flat surfaces and the steel disc. Acetone is used to clean the specimens $\&$ wear track. The wear rate is determined by the weight loss method.

A steel disc as conterbody was used, to promote a mechanically mixed layer. It was found from the literature that, the presence of major alloying elements in the Alalloy that have high solubility in steel promoted a thick mechanically mixed layer. The solubility of Al-alloy elements in Fe is in the order of $\mathrm{Si}, \mathrm{Mn}, \mathrm{Cu}, \mathrm{Mg}$, which roughly approximates the thickness of the mechanically mixed layer formed, while the Fe content of the mechanically mixed layer also scaled in this order. As for the ceramic material, which also can be used as a conterbody during the wear test, the mechanically mixed layer was derived from fracture of the slider, and also from transfer and retransfer of the aluminium alloy. To analyze the true effect of the work hardening induced by wear, a ceramic slider was used, to minimize the formation of a mechanically mixed layer [21].

\section{Results and discussions}

The wear tracks obviously specify the high magnitude of crater lines intimately packed at a high weight percentage of reinforcement as shown in Fig. $3 a$.

Figure $3 \mathrm{~b}$ shows the scanning electron microscope (SEM) images hybrid aluminum metal matrix composites (age hardening). The allocation of the Silicon carbide and alumina particle in the aluminum matrix composites [23] is noticed a by the homogeneous uniform circulation of the reinforcements in the matrix is necessary to form a composite with standardized mechanical properties. The agglomeration of particles is small. The worn surface 


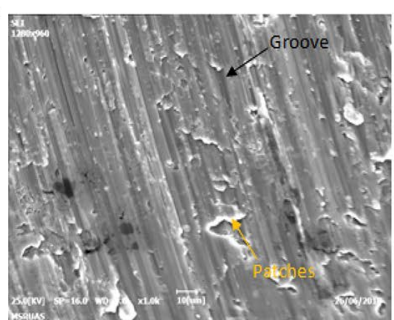

(a) Al7075

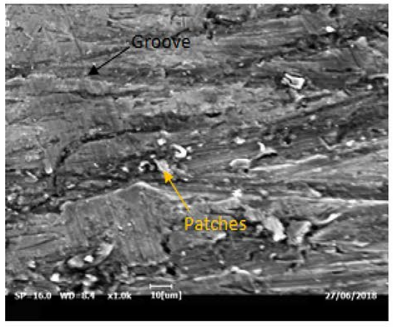

$\mathrm{Al} 7075+10 \% \mathrm{SiC}+10 \% \mathrm{Al}_{2} \mathrm{O}_{3}$

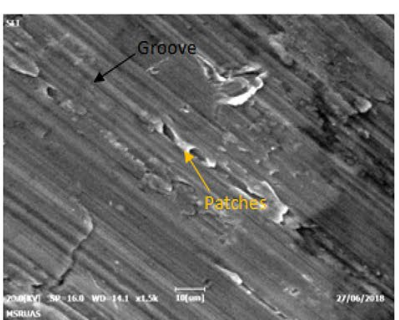

$\mathrm{Al} 7075+5 \% \mathrm{SiC}+5 \% \mathrm{Al}_{2} \mathrm{O}_{3}$

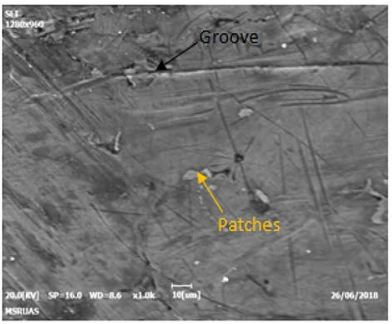

$\mathrm{Al} 7075+15 \% \mathrm{SiC}+15 \% \mathrm{Al}_{2} \mathrm{O}_{3}$

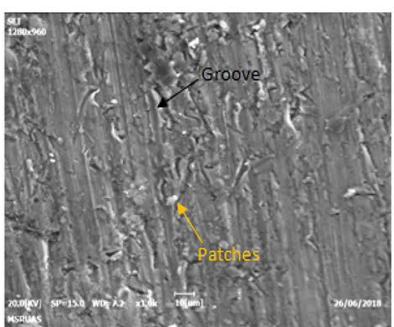

(b) Al7075

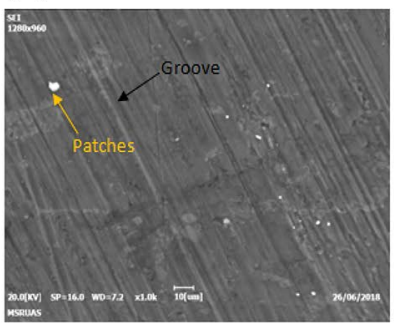

$\mathrm{Al} 7075+5 \% \mathrm{SiC}+5 \% \mathrm{Al}_{2} \mathrm{O}_{3}$

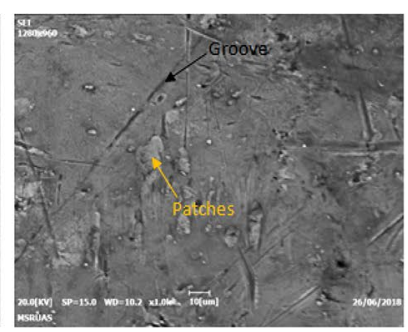

$\mathrm{Al} 7075+10 \% \mathrm{SiC}+10 \% \mathrm{Al}_{2} \mathrm{O}_{3} \quad \mathrm{Al} 7075+15 \% \mathrm{SiC}+15 \% \mathrm{Al}_{2} \mathrm{O}_{3}$

Fig. 3 Worn surface of HAMMCs $\mathbf{a}$ as-cast, $\mathbf{b}$ age hardened

Fig. 4 Influence of load on wear-rate at $848.23 \mathrm{~m}$

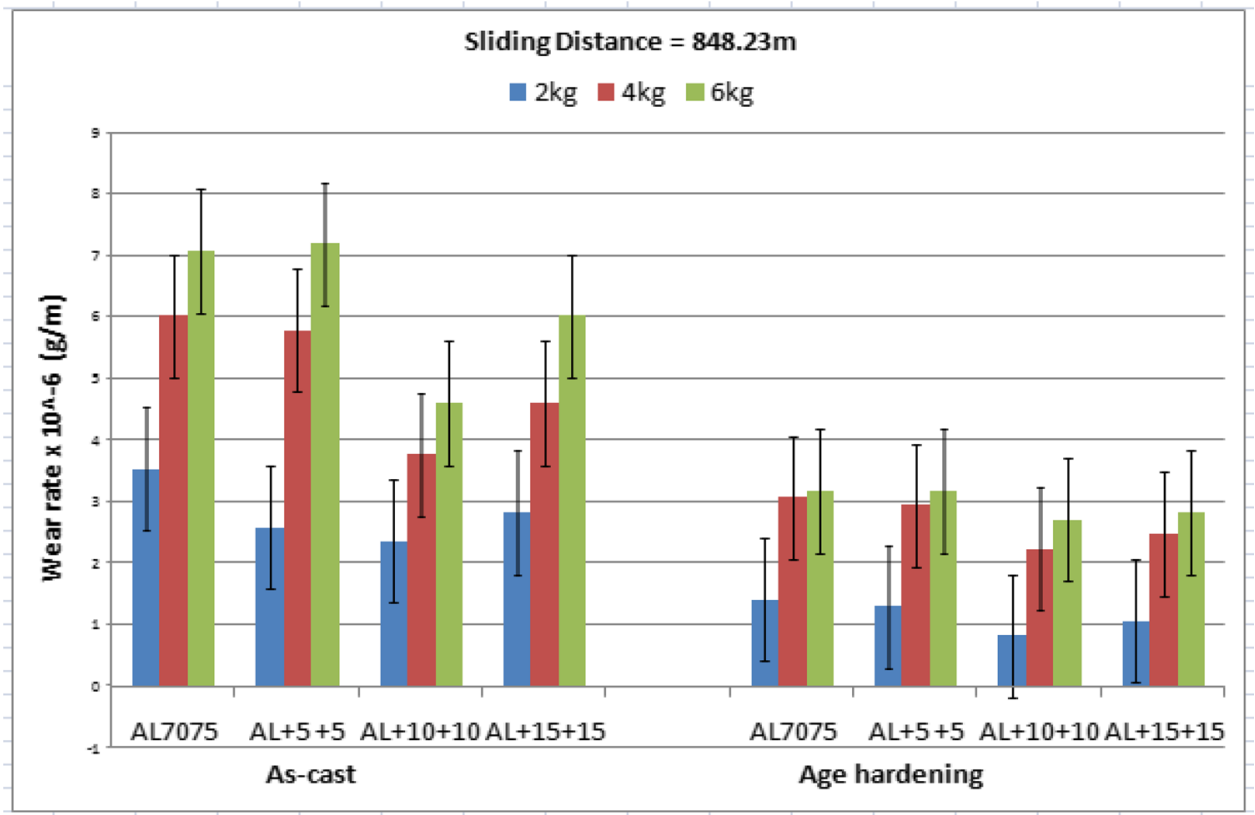

of the metal matrix composites leads to the formation of iron-rich layers. The worn surface Fig. 3a, b show the white patches of iron oxide and exposed particles on the contact surface of $\mathrm{Al} 7075+10 \% \mathrm{SiC}+10 \% \mathrm{Al}_{2} \mathrm{O}_{3}$ hybrid aluminum metal matrix composites. Development of the $\mathrm{FeO}_{2}$ was less significant at medium load than that of lesser loads. The occurrence of aluminum-oxide and silicon carbide was seen at the morphological surface. Figure $3 a, b$ illustrate the features of the worn surface of
Al7075-10\% $\mathrm{SiC}-10 \% \mathrm{Al}_{2} \mathrm{O}_{3}$ hybrid aluminum metal matrix composites.

Figure 4 shows the comparison of as-cast and age hardened hybrid aluminum metal matrix composites for different load and at a sliding distance of $848.23 \mathrm{~m}$. In the metal matrix composites (MMCs) increase wt\% of $\mathrm{SiC}+\mathrm{Al}_{2} \mathrm{O}_{3}$ reinforcement improves the hardness. Addition of hard particulate reinforcement in the composites restricts the composites from getting soft. It results in reductions in the 
Fig. 5 EDX profile analysis Al7075-10 wt $\%$ of $\mathrm{SiC} / \mathrm{Al}_{2} \mathrm{O}_{3}$ composite surface after wear test

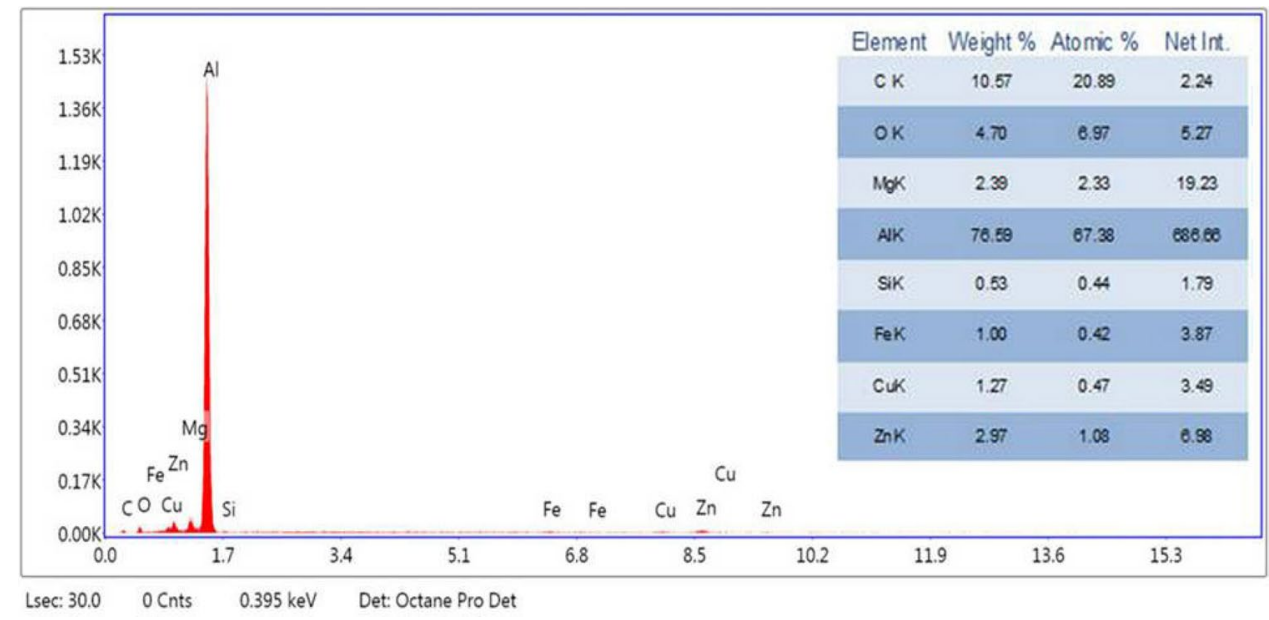

wear rate. It was observed that the volumetric wear rate decreased in heat treated hybrid aluminum metal matrix composites with increased $\mathrm{SiC}+\mathrm{Al}_{2} \mathrm{O}_{3}$ reinforcement and aging when compared with the base alloy the weight loss was decreased $[23,24]$ in metal matrix composites. In hybrid aluminum metal matrix composites the weight loss was further reduced when compared with aged conditions. Remarkably the lowest weight loss was observed in $\mathrm{Al} 7075-10 \mathrm{wt} \% \mathrm{SiC}-10 \mathrm{wt} \% \mathrm{Al}_{2} \mathrm{O}_{3}$ with aged hybrid aluminum metal matrix composites.

At 15 wt\% of reinforcement, it is observed that decrease of wear rate on increment of sliding distance. With increase of sliding distances tribo-oxidation intensify. More tribooxides results in the decrease of coefficient of friction and wear rate.

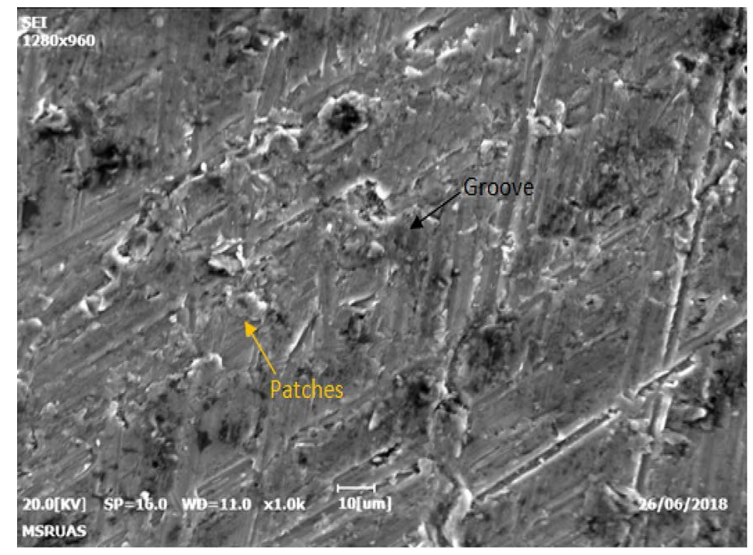

$\mathrm{Al} 7075+10 \% \mathrm{SiC}+10 \% \mathrm{Al}_{2} \mathrm{O}_{3}$ at $6 \mathrm{Kg}, 600 \mathrm{RPM}$
Figure 5 shows the element analysis of the said hybrid composite material after wear test. The solubility of Alalloy elements in Fe is in the order of $\mathrm{Si}, \mathrm{Mn}, \mathrm{Cu}, \mathrm{Mg}$, which roughly approximates the thickness of the mechanically mixed layer formed, while the Fe content of the mechanically mixed layer also scaled in this order.

Table in the Fig. 5 describes the atom percentage of iron, silicon, magnesium, carbon, and aluminum. The content of silicon, zinc and magnesium indicates that the presence of $\mathrm{Si}, \mathrm{Zn}$ and $\mathrm{Mg}$ in the Al7075 alloy. The presence of the Fe is the effect of steel counterbody. Due to the rubbing of the pin on the disc material there is a formation of iron content on the surface of the composite body. This form a layer on the surface of the composite is referred as mechanically mixed layer.

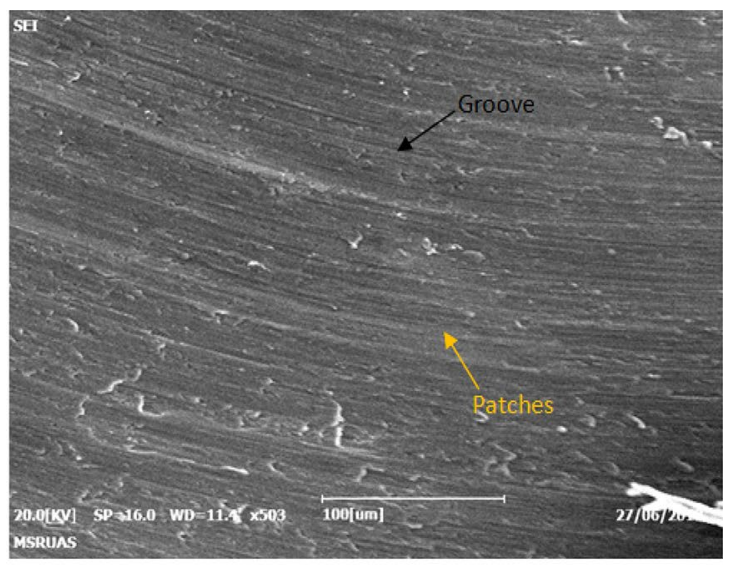

$\mathrm{Al} 7075+10 \% \mathrm{SiC}+10 \% \mathrm{Al}_{2} \mathrm{O}_{3}$ at $6 \mathrm{Kg}, 600 \mathrm{RPM}$

Fig. 6 Worn surface of HAMMCs $\mathbf{a}$ as-cast, $\mathbf{b}$ age hardening 


\section{Mechanically mixed layer}

\subsection{Description of the mechanically mixed layer (MML)}

Figure $6 \mathrm{a}, \mathrm{b}$ demonstrates scanning electron microscope pictures of the hybrid aluminum metal matrix composites wear surface. The scanning electron microscope illustrates various lengthy groove, craters on the worn surface with the increment in load to $58.86 \mathrm{~N}$ at sliding speeds of $2.827 \mathrm{~m} / \mathrm{s}$. due to increase in load, the composite wear behaviour change starting abrasion to delamination from the scanning electron microscope picture. It is plainly seen that the mechanically mixed layer are somewhere in the range of three and five times harder than the AA7075 alloy.

The particles present beneath the layer were hard, brittle than the matrix alloy. Mechanically Mixed Layer shows hardness around 6 times better while comparing to bulk composite $[16,17]$. Mechanically Mixed Layer was absent on the worn surface of the aluminum. Presence of these layers probably restricts the rate of wear [18]. It is revealed to facilitate aluminum experienced a change from conversion from mild to severe wear at $58.86 \mathrm{~N}$. It is comprehensible that the mechanically mixed layer available on specimens experienced at load in the mild wear zone while the mechanically mixed layer was deficient on specimens which experienced severe wear. Due to the superior rate of wear temperature raises at the specimen sliding surface, the pin is softened and results in plastic, it reacts with $\mathrm{O}$ and results in oxides. The attention of the interface layer affects the rate of wear. As the raise in the reinforcements the thickness of the mechanically mixed layer increases.

\subsection{Effect of thickness of mechanically mixed layer}

For as-cast and age hardened hybrid aluminum metal matrix composites, thickness analysis using a scanning electron microscope is carried out for this purpose. For this rate of wear was generally not sensitive to the thickness of mechanically mixed layer for the Al7075, in spite of the fact that rate of wear decremented in a linear mode with incrementing thickness of the mechanically mixed layer. Figures 7 and 8 shows the thickness of as-cast and age hardened hybrid aluminum metal matrix composites determined using scanning electron microscope analysis.
Fig. 7 SEM images showing thickness of mechanically mixed layer at as-cast condition a Al7075, b $\mathrm{Al} 7075+5 \% \mathrm{SiC}+5 \% \mathrm{Al}_{2} \mathrm{O}_{3}$, c Al7075+10\% SiC + $10 \% \mathrm{Al}_{2} \mathrm{O}_{3}$, d $\mathrm{Al} 7075+15 \% \mathrm{SiC}+15 \% \mathrm{Al}_{2} \mathrm{O}_{3}$

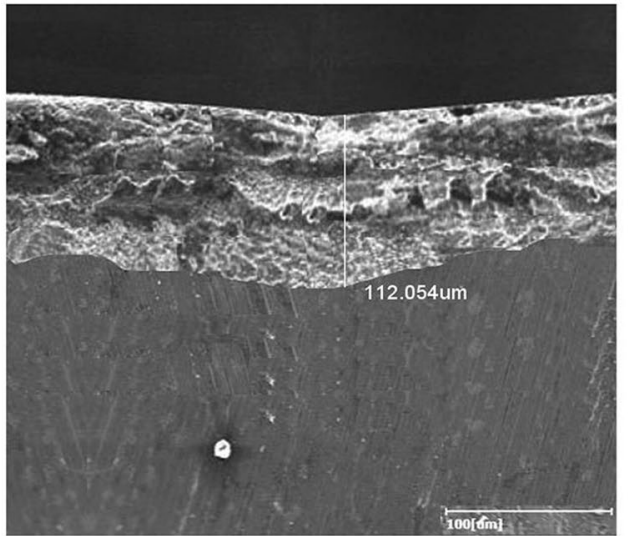

(a)

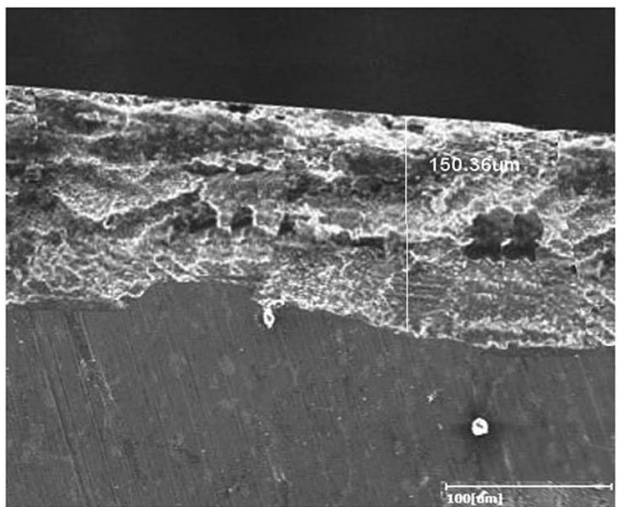

(c)

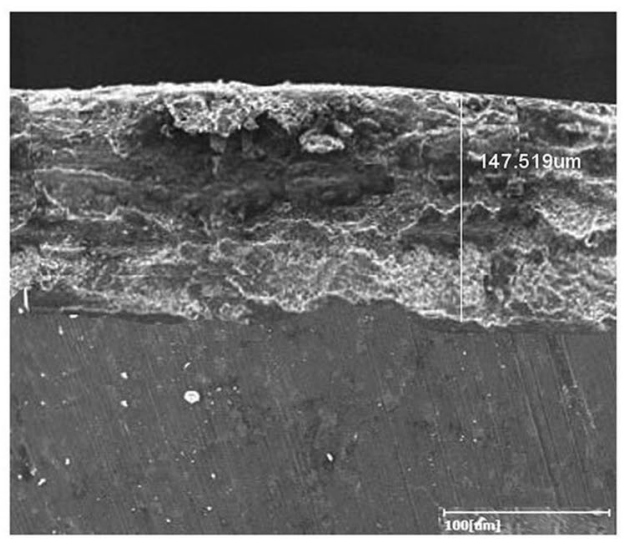

(b)

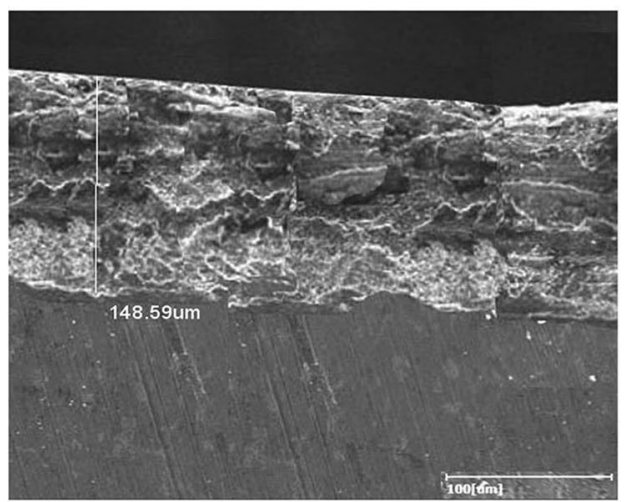

(d)

SN Applied Sciences a SPRINGer NATURE journal 
Fig. 8 SEM images showing thickness of MML at age hardening condition a Al7075, b $\mathrm{Al} 7075+5 \% \mathrm{SiC}+5 \% \mathrm{Al}_{2} \mathrm{O}_{3}$, c $\mathrm{Al} 7075+10 \% \mathrm{SiC}+10 \% \mathrm{Al}_{2} \mathrm{O}_{3}$, d $\mathrm{Al} 7075+15 \% \mathrm{SiC}+15 \% \mathrm{Al}_{2} \mathrm{O}_{3}$

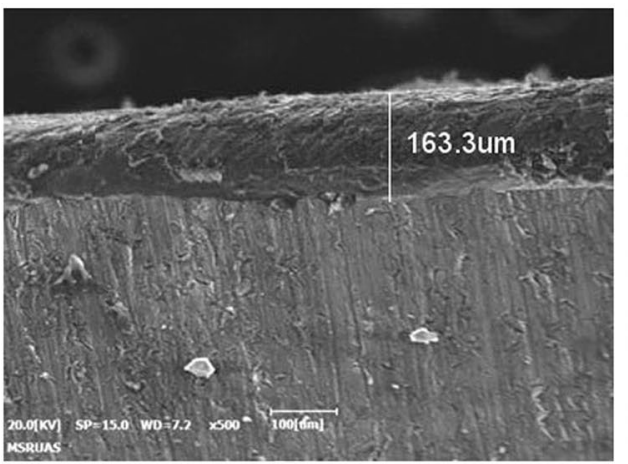

(a)

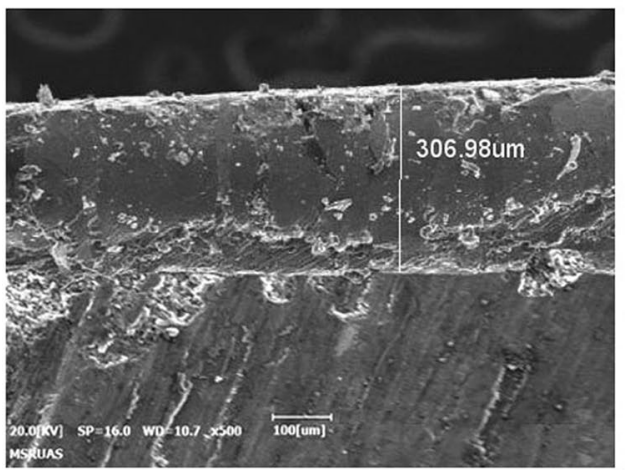

(c)

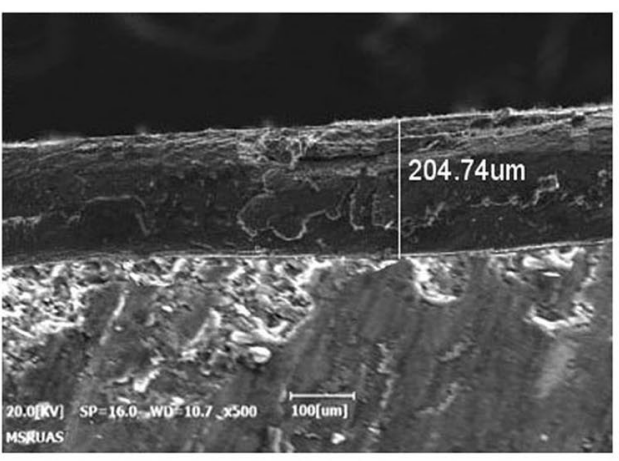

(b)

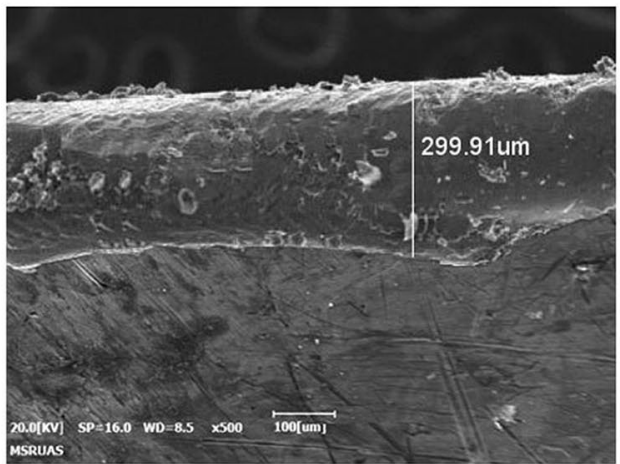

(d)

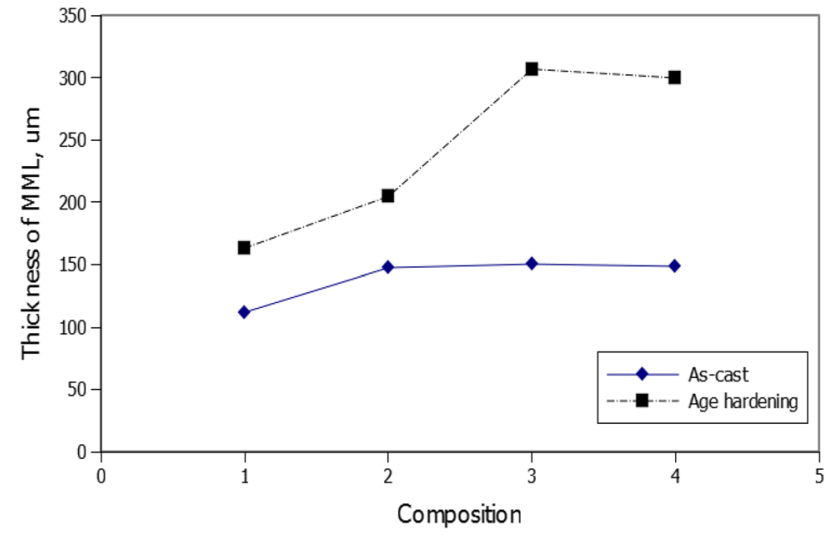

Fig. 9 Comparison of the thickness of MML for as-cast and age hardened conditions

Mechanically mixed layer generated is of wave-like formation [23] as shown in the Figs. 7 and 8.

Figure 9 shows the comparison of as-cast and age hardened hybrid aluminum metal matrix composites for the thickness of the mechanically mixed layer. From the scanning electron microscope analysis, it is clear that the rate of wear was a strong function.

Further, on a study of this analysis, it is seen that production of the mechanically mixed layer on the composite worn surface, increases with increasing reinforcement content. These results also show that higher reinforcement content leads to greater material transfer from the counter surface with consequent faster development of a protective mechanically mixed layer on the worn surface.

It shows that raise in vol\% of silicon carbide and $\mathrm{Al}_{2} \mathrm{O}_{3}$ increments the thickness of mechanically mixed layer lying on the pin surface. The mechanically mixed layer thickness at $58.56 \mathrm{~N}$ for various range of compositions and as composition increases thickness of the mechanically mixed layer increases up to $10 \%$ for both the reinforcements and it is decreased at $15 \%$ reinforcements due to agglomeration It is to be noted that while the thickness of the mechanically mixed layer increases with incrementing load in the mild wear region. The mechanically mixed layer was seen in all the test materials, particularly in the mild wear regime. The mechanically mixed layer was seen only in the mild wear zone. 


\section{Conclusions}

From the investigation, the following conclusions were drawn on the mechanical and wear performance of ascast and $\mathrm{T} 6$ ageing of hybrid aluminium metal matrix composites-Al7075-SiC- $\mathrm{Al}_{2} \mathrm{O}_{3}$. Wear resistance of $\mathrm{Al} 7075 / \mathrm{Al}_{2} \mathrm{O}_{3}+\mathrm{SiC}$ composites incremented with weight percentage. The reduction in the rate of wear with sliding distances, composition. It enhances with loads for age hardening and without age hardening. The age hardened $\mathrm{Al}-7075 / \mathrm{Sic}+\mathrm{Al}_{2} \mathrm{O}_{3}$ Composite shows excellent resistance to wear while comparing to $\mathrm{Al} 7075 / \mathrm{Al}_{2} \mathrm{O}_{3}+\mathrm{SiC}$ it has the distinctive property as the addition of Silicon-carbide and Aluminum-oxide. The microstructural characterization discovered that the homogeneous circulation of the particle in the matrix system with a minimal amount of porosity. The micro-structural studies of the scanning electron microscope and EDX techniques shows the homogeneous distribution of the particulates in the hybrid composites.

In T6 heat treated (age hardening) Al7075-10 wt\% $\mathrm{SiC}+10$ wt $\% \mathrm{Al}_{2} \mathrm{O}_{3}$ hybrid aluminum metal matrix composites improved the wear resistance was observed when compared with base alloy. Highest resistance to wear was observed in $\mathrm{Al} 7075-10 \mathrm{wt} \% \mathrm{SiC}+10 \mathrm{wt} \% \mathrm{Al}_{2} \mathrm{O}_{3}$ due to the presence of reinforcements. Further, it is observed the decrement in wear rate with increment in weight per cent of reinforcement for the desired sliding distances. From the investigation, it was concluded that composites containing $10 \%$ weight of silicon carbide and $10 \%$ weight of aluminum oxide reinforcements with ageing exhibited superior mechanical and tribological properties.

It is noticed that mechanically mixed layer presence in the mild wear regime, it is absence in the severe wear regime. Therefore, it is noticed non-formation of the mechanically mixed layer is dependable for the onset of severe wear. It is noticed that reducing the rate of wear with increment in mechanically mixed layer thickness. The mechanically mixed layer thickness increases by rising reinforcement composition up to $10 \%$ the development of hard mechanically mixed layer (stable, thin) layer will give the finest resistance to wear.

Acknowledgements I wish to thank University B.D.T. College of Engineering (Davangere), DST-PURSE Laboratory of Mangalore University, VGST-K FIST facility for melting and Material Testing (SJMIT, Chitradurga) for their support in providing facilities for various characterizations of materials and helped me to complete this research work.

\section{Compliance with ethical standards}

Conflict of interest The authors declare that they have no conflict of interest.

\section{References}

1. ASM Handbook (2001) Composites, ASM International, p 21

2. Miller DM (1987) Glass fibers, composites, engineered materials handbook. ASM Int 1:45-48

3. Doddamani S, Kaleemulla M, Begum Y, Anand KJ (2017) An investigation on wear behavior of graphite reinforced aluminum metal matrix composites. JoRSTEM 2017:1-6

4. Rajesh AM, Kaleemulla M (2016) Experimental investigations on mechanical behavior of aluminum metal matrix composites. Mater Sci Eng. https://doi.org/10.1088/1757-99x/149/1/012121

5. Rajesh AM, Kaleemulla M (2016) Experimental investigations on mechanical and wear behavior of hybrid aluminum alloy. IJERT 05(13):128-131

6. Rajesh AM, Kaleemulla M (2017) Effect of heat treatment on hybrid aluminum metal matrix composites. Int J Emerg Res Manag Technol 6(5):548-551

7. Rajesh AM, Kaleemulla M, Doddamani S (2019) Effect of addition of $\mathrm{SiC}$ and $\mathrm{Al}_{2} \mathrm{O}_{3}$ on wear behavior of hybrid aluminum metal matrix composites. ACTA Tech Corviniensis Bull Eng 12(1):43-52

8. Song WQ, Kraulis P, Mourrtz AP (1995) The effect of thermal ageing on the abrasive wear behaviour of age-hardening $2014 \mathrm{Al} /$ $\mathrm{SiC}$ and $6061 \mathrm{Al} / \mathrm{SiC}$ composites. Wear 85:125-130

9. Radhika N (2018) Analysis of three body abrasive wear behaviour of centrifugally cast aluminum composite reinforced with $\mathrm{Ni}$ coated SiC using taguchi technique. Tribol Ind 40(1):81-91. https://doi.org/10.24874/ti.2018.40.01.07

10. Paulo Davim J, Conceicao Antonio CA (2001) Optimal drilling of particulate metal matrix composites based on experimental and numerical procedures. Int Mach Tools Manuf 41:21-31

11. Alpas T, Zhang J (1994) Effect of microstructure (particulate size and volume fraction) and counter face material on the sliding wear resistance of particulatereinforced aluminum matrix composites. Metall Mater Trans A 25:969-983

12. Zhang J, Alpas AT (1997) Transition between mild and severe wear in aluminum alloys. Acta Mater 45:513

13. Wilson S, Alpas AT (1996) Effect of temperature on the sliding wear performance of $\mathrm{A} 1$ alloys and $\mathrm{A} 1$ matrix composites. Wear 196:270-278

14. Uyyuru RK, Surappa MK, Brusethaug S (2007) Tribological behavior of $\mathrm{Al}-\mathrm{Si}-\mathrm{SiCp}$ composites/automobile brake pad system under dry sliding conditions. Tribol Int 40:365-373

15. Hassan AM, Alrashdan A, Hayajneh MT, Mayyas AT (2009) Wear behavior of $\mathrm{Al}-\mathrm{Mg}-\mathrm{Cu}$-based composites containing $\mathrm{SiC}$ particles. Tribol Int 42:1230-1238

16. Venkataraman B, Sundararajan $G$ (1996) The sliding wear behaviour of $\mathrm{Al}-\mathrm{SiC}$ particulate composites. II. The characterization of subsurface deformation and correlation with wear behaviour. Acta Metall Mater 44:461-473

17. Venkataraman B, Sundararajan G (2000) Correlation between the characteristics of the mechanically mixed layer and wear behaviour of aluminum, Al-7075 alloy and Al-MMCs. Wear 245:22-38

18. Tyagi R (2005) Synthesis and tribological characterization of in situ cast Al-TiC composites. Wear 259:569-575

19. Riahi AR, Alpas AT (2001) The role of tribo-layers on the sliding wear behaviour of graphitic aluminum matrix composites. Wear 251:1396-1407

20. Prasad PR, Ray S, Gaindhar JL, Kappor ML (1985) Mechanical properties of Al-10\% Cu alloy particulate composites. Scr Mater 19:1019-1022

21. Rosenberger MR, Forlererc E, Schvezova CE (2009) Wear behavior of AA1060 reinforced with alumina under different loads. Wear 266:356-359 
22. Las L, Rodrigez Ibabe JM (2003) Wear behaviour of eutectic and hypereutectic $\mathrm{Al}-\mathrm{Si}-\mathrm{Cu}-\mathrm{Mg}$ casting alloys tested against a composite brake pad. Mater Sci Eng, A 363:193-200

23. Rajesh AM, Kaleemulla M, Doddamani S (2019) Material characterization of $\mathrm{SiC}$ and $\mathrm{Al}_{2} \mathrm{O}_{3}$ reinforced hybrid aluminum metal matrix composites on wear behavior. Adv Compos Lett SAGE 28:1-10. https://doi.org/10.1177/0963693519856356

24. Rajesh AM, Kaleemulla M, Doddamani S (2019) Effect of heat treatment on wear behavior of hybrid aluminum metal matrix composites. Tribol Ind 41:1-11. https://doi.org/10.24874/ ti.2019.41.03.04
25. Ghazali MJ, Rainforth WM, Jones H (2005) Dry sliding wear behaviour of some wrought, rapidly solidified powder metallurgy aluminum alloys. Wear 259:490-500

Publisher's Note Springer Nature remains neutral with regard to jurisdictional claims in published maps and institutional affiliations. 